\title{
Micheline Cellier - Claire Torreilles - Marie Jeanne Verny, Entre deux langues. Bilinguisme et autobiographie. Textes commentés
}

\section{Giovanni Agresti}

\section{(2) OpenEdition}

\section{Journals}

\section{Édition électronique}

URL : http://journals.openedition.org/studifrancesi/36912

DOI : 10.4000/studifrancesi.36912

ISSN : 2421-5856

Éditeur

Rosenberg \& Sellier

\section{Édition imprimée}

Date de publication : 1 juillet 2005

Pagination : 217

ISSN : 0039-2944

\section{Référence électronique}

Giovanni Agresti, «Micheline Cellier - Claire Torreilles - Marie Jeanne Verny, Entre deux langues. Bilinguisme et autobiographie. Textes commentés », Studi Francesi [En ligne], 145 (XLIX | I) | 2005, mis en ligne le 30 novembre 2015, consulté le 18 avril 2021. URL : http://journals.openedition.org/ studifrancesi/36912 ; DOI : https://doi.org/10.4000/studifrancesi.36912

Ce document a été généré automatiquement le 18 avril 2021.

\section{cc) (†) $\odot$}

Studi Francesi è distribuita con Licenza Creative Commons Attribuzione - Non commerciale - Non opere derivate 4.0 Internazionale. 


\title{
Micheline Cellier - Claire Torreilles - Marie Jeanne Verny, Entre deux langues. Bilinguisme et autobiographie. Textes commentés
}

\author{
Giovanni Agresti
}

\section{RÉFÉRENCE}

MICHELINE CELLIER - CLAIRE TORREILLES - MARIE JEANNE VERNY, Entre deux langues. Bilinguisme et autobiographie. Textes commentés, Paris, ADAPT Édtions, 2004, pp. 144.

1 Ce manuel de français (quoique quelques-uns des textes commentés soient d'auteurs non francophones) propose des séquences didactiques - avec axes de lectures, commentaires et encarts (notamment sur l'autobiographie, l'énonciation, la diglossie) sur des textes d'écrivains de double culture qui s'expriment en deux langues (deux langues nationales ou nationale et régionale) en interférence ou conflit, mais également chères. Cette problématique originale, en rapport avec les notions de bilinguisme, de diglossie et de francophonie, renouvelle utilement la perspective autobiographique, la double culture exacerbant le rapport au monde et posant de façon plus aiguë le problème de l'identité en train de se constituer.

Le volume est structuré en trois parties - «Le moi en question» (avec des textes de Lafont, Sarraute, Memmi, Garat, Fusina, Bianciotti, Canetti, Milovanoff), «La langue de l'école» (Duneton, Millet, Lavergne, Hélias, Chamoiseau, Dib, Péguy, Gouzy, Landart, Miron), «la langue de la création» (Laumesfeld, Pécout, Weckmann, Pasolini, Alexakis, Chamson, Makine, Kundera) - d'après un ordre qui serait, en général, celui d'une sorte de libération du sujet par rapport au conflit intérieur dû à la négation, le plus souvent, de la langue maternelle, affective - négation exercée par la culture et la langue dominantes. Ce processus aboutit en effet à la création littéraire profitant, aussi, «du 
«jeu» entre les langues et offrant des possibilités de dépassement de la contradiction et de la déchirure» (p. 9), jeu qui est d'ailleurs un des thèmes et des moteurs majeurs de la littérature occitane contemporaine, dont Marie-Jeanne Verny et Claire Torreilles figurent parmi les défenseurs les plus actifs depuis bien des années. 